\title{
Indentation response of a NiTi shape memory alloy: modeling and experiments
}

\author{
C. Maletta, F. Furgiuele, E. Sgambitterra \\ Dept. of Mechanical Engineering, University of Calabria, 87036 Rende (CS), Italy. \\ carmine.maletta@unical.it
}

\author{
M. Callisti, B. G. Mellor, R. J.K. Wood \\ Engineering Sciences, University of Southampton, UK. \\ mc3a09@soton.ac.uk
}

\begin{abstract}
The indentation response of a pseudoelastic nickel-titanium based shape memory alloy (SMA) has been analyzed. Indentation tests have been carried out at room temperature using a spherical diamond tip and indentation loads in the range $50-500 \mathrm{mN}$ in order to promote a large stress-induced transformation zone in the indentation region and, consequently, to avoid local effects due to microstructural variations. The measured load-displacement data have been analyzed to obtain information on the pseudoelastic response of the alloy. To aid this analysis numerical simulations were performed, by using a commercial finite element (FE) software code and a special constitutive model for SMAs, so as to understand better the microstructural evolution occurring during the indentation process. Finally, the FE model has been used to analyze the effects of temperature on the indentation response of the alloy. This analysis revealed a marked variation of both the maximum and residual penetration depths with increasing test temperature.
\end{abstract}

SOMMARIO. Nel presente lavoro è stata analizzata la risposta all'indentazione di una lega a memoria di forma (SMA - Shape Memory Alloy) a base di nickel e titanio. In particolare, sono state eseguite prove di indentazione mediante l'utilizzo di un indentatore sferico e per livelli di carico compresi tra 50 e $500 \mathrm{mN}$, al fine di favorire la formazione di zone di trasformazione ampie e, pertanto, evitare effetti locali dovuti a variazioni microstrutturali. Le curve carico-spostamento sono state analizzate al fine di ottenere informazioni utili per la comprensione del comportamento pseudoelastico della lega. A tale scopo, sono state condotte analisi numeriche, utilizzando un software commerciale agli elementi finiti, per meglio comprendere i cambiamenti microstrutturali, che avvengono durante il processo di indentazione. Infine, il modello numerico è stato utilizzato per analizzare l'effetto della temperatura sulla risposta all'indentazione delle SMAs. I risultati hanno mostrato una marcata variazione della profondità di penetrazione e della profondità residua al variare della temperatura.

KEYWORDS. Shape Memory alloys; Indentation tests; Finite element simulations.

\section{INTRODUCTION}

$\mathrm{N}$ ickel-titanium (NiTi) based shape memory alloys (SMAs) have, over recent decades, attracted the interest of the scientific and engineering community due to their unique functional properties, namely the pseudoelastic effect (PE) and the shape memory effect (SME) [1], coupled with their good mechanical properties and biocompatibility. The unique functional response of NiTi alloys is due to a reversible solid state phase transformation between a parent phase (austenite) and a product phase (martensite), the so called thermoelastic martensitic 
transformation (TMT); the latter is a diffusionless phase transition which can be activated either by temperature (thermally-induced martensitic transformation, TIM) or by applied stress (stress-induced martensitic transformation, SIM) [1]. As a result of these microstructural changes, NiTi alloys show high recovery capabilities (up to a maximum deformation of $12 \%$ ), by either raising the temperature of the material above the characteristic transition temperatures (SME) or by removing the mechanical load (PE).

However, despite the increasing interest and the efforts of many researchers to understand these unusual mechanisms, the use of NiTi alloys is currently limited to high-value applications (e.g. medical devices, MEMS, etc.), due to high raw material and manufacturing costs, the latter resulting from the need to control precisely the processing parameters since the functional and mechanical properties of NiTi alloys are significantly affected by the thermo-mechanical loading history experienced during manufacturing. The design of NiTi based components also needs accurate knowledge of the mechanical and functional response of the material, as well as how this evolves during subsequent thermo-mechanical processes. In addition, as most NiTi components are characterized by complex shape and small size scale (e.g. endovascular stents, micro-surgery devices, MEMS etc.) their properties cannot be directly obtained from the bulk raw material. Thus the use of non-destructive techniques to analyze the mechanical and functional properties of small volumes of material is essential. Among the techniques available, nanoindentation is widely used to measure mechanical properties [2], such as hardness, elastic modulus, scratch resistance, creep, etc., of small volumes of materials with negligible damage to the surface. However, despite the aforementioned advantages, various difficulties arise in analyzing the mechanical properties of SMAs from the indentation response, due to micro-structural changes, such as phase transition and martensite variant re-orientation. In fact, the latter is expected to play a significant role in the indentation response of SMAs, as this takes place in the indentation region due to the presence of highly localized stresses. As a consequence, well known contact mechanics theories for conventional metals cannot be directly applied to SMAs and work has been carried out, in recent years, to understand better the effects of microstructural transitions on the indentation response of both thin films [3-8] and bulk specimens [9-15]. These studies revealed marked effects of material composition, as well as the thermo-mechanical treatments carried out during material processing, on the indentation response of SMAs. In particular, both the mechanical and thermal recovery mechanisms of nanoindents have been analyzed in order to study the pseudoelastic and shape memory capabilities of the alloys, respectively. Furthermore, the effects of the test temperature on the indentation response of a pseudoelastic alloy have been analyzed [11] by numerical simulations. In addition, a method to estimate the phase transformation stresses of a pseudoelastic alloy has been proposed in [13], based on comparing the indentation response of the SMA with that of a conventional elastic material. Finally, cyclic instrumented indentation was carried out in [14] so as to capture the stress-induced phase transition mechanisms from the experimentally measured load-displacement curves. However, notwithstanding the encouraging results obtained recently, considerable research needs to be carried out to elucidate the relationship between the indentation response of SMAs and their mechanical and functional properties.

In this study a commercial pseudoelastic NiTi alloy (Type S, Memory Metalle, Germany) has been analyzed by indentation tests and finite element analysis. In particular, indents have been made at room temperature using a spherical diamond indenter and indentation loads in the range $50-500 \mathrm{mN}$, in order to promote a large stress-induced transformation zone in the indentation region and, consequently, to avoid local effects due to microstructural variations.

Experimentally measured force-displacement curves have been analyzed to obtain information on the pseudoelastic response of the alloy. Furthermore, Finite Element (FE) simulations were developed, by using a special constitutive model for SMAs implemented in a commercial FE software code, to study the microstructural mechanisms occurring during indentation. The FE models have been used to analyze the stress induced transformation zone in the indentation region and systematic analyses have been carried out to understand better the relationship between the nanoindentation response and the typical thermo-mechanical parameters of SMAs. Finally, the FE model has been used to analyze the effects of temperature and transformation stresses, calculated from the Clausius-Clapeyron relationship, on the indentation response of the alloy.

\section{MATERIAL AND METHODS}

\section{Material}

commercial pseudoelastic NiTi sheet (Type S, Memory metalle, Germany), with a nominal chemical composition of 50.8 at. $\%$ Ni-49.2 at. $\%$ Ti and thickness $t=1.5 \mathrm{~mm}$, has been used in this investigation. It was supplied in the flat annealed condition. The raw material was first analyzed by Differential Scanning Calorimetry (DSC) and standard tensile tests in order to determine the main thermo-mechanical parameters of the alloy. Fig. 1.a illustrates the 
DSC thermogram of the raw material which was obtained at a heating/cooling rate of $1.6 \mathrm{Ks}-1$ in the temperature range $100^{\circ} \mathrm{C}$ to $100^{\circ} \mathrm{C}$. This analysis revealed the presence of a two-stage phase transformation $\left(\mathrm{B} 2 \rightarrow \mathrm{R} \rightarrow \mathrm{B} 19^{\prime}\right)$ during cooling, with the presence of R-phase (Rhombohedral phase), while a single-stage phase transformation (B2 $\rightarrow$ B19') was observed during heating, as is usual in Ni-rich NiTi alloys. The figure also gives the values of the transformation temperatures $\left(\mathrm{M}_{\mathrm{s}}\right.$, $\mathrm{M}_{\mathrm{f}}, \mathrm{A}_{\mathrm{s}}, \mathrm{A}_{\mathrm{f}}, \mathrm{R}_{\mathrm{s}}$ and $\mathrm{R}_{\mathrm{f}}$ ), which have been estimated by the tangent line method; the alloy shows an austenite finish temperature $\mathrm{A}_{\mathrm{f}}=13,7^{\circ} \mathrm{C}$, which indicates a fully austenitic structure at room temperature, i.e. the alloy exhibits a pseudoelastic response. Fig. 1.b presents a stress-strain curve of the alloy obtained from an isothermal $(T=298 \mathrm{~K})$ displacement controlled loading-unloading cycle up to a maximum deformation of $6.2 \%$ which corresponds to the maximum deformation of the stress-strain transformation plateau. The figure also shows the values of the main mechanical parameters of the alloy, Young's moduli $\left(E_{A}\right.$ and $\left.E_{M}\right)$, transformation stresses $\left(\sigma_{A M}^{s}, \sigma_{A M}^{f}, \sigma_{M A}^{s}, \sigma_{M A}^{f}\right)$ and transformation strain $\left(\varepsilon_{L}\right)$, together with the Clausius-Clapeyron constants $\left(C_{A}=d \sigma_{M A} / d T, C_{M}=d \sigma_{A M} / d T\right)$, which have been obtained from isothermal tests carried out at different temperatures.

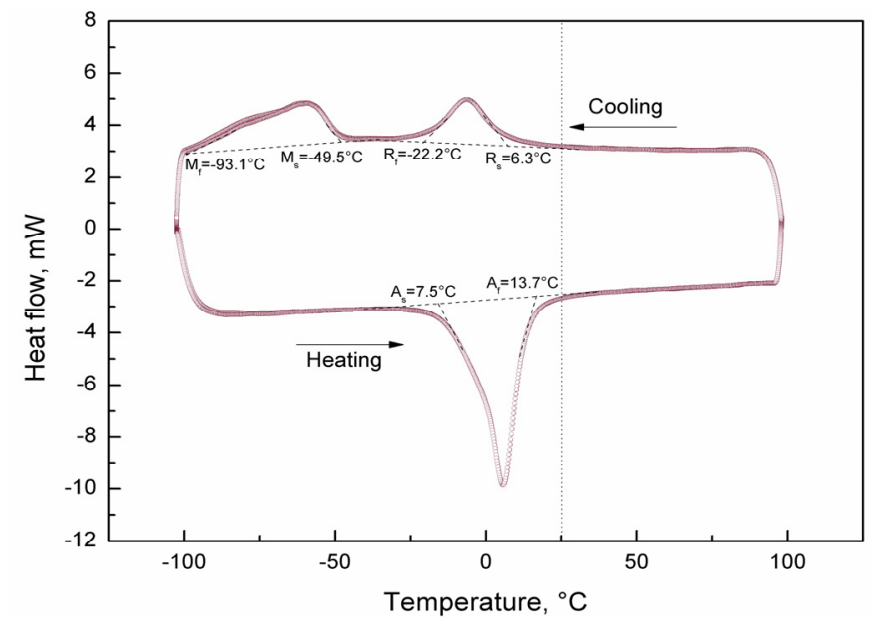

(a)

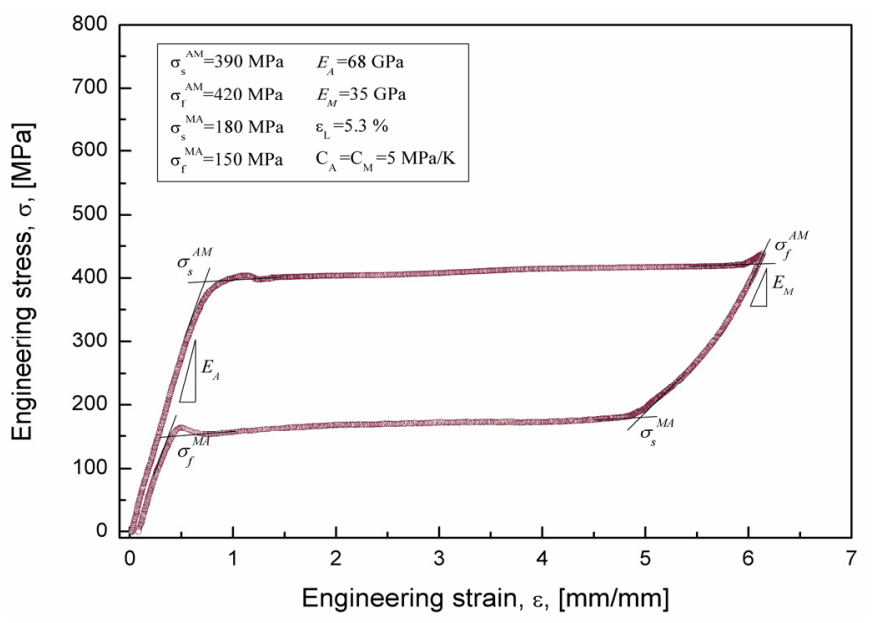

(b)

Figure 1: Thermo-mechanical properties of the alloy investigated: a) DSC thermograph with transformation temperatures and b) Loading-unloading isothermal stress-strain cycle (298 K).

\section{Indentation tests}

The indentation response of the alloy investigated has been determined by using a NanoTest 600 (Micro Materials Ltd, United Kingdom) nanoindenter. Rectangular shaped samples $(20 \mathrm{~mm}$ x $10 \mathrm{~mm}$ ), were cut from the as-received sheet and prepared, prior to indentation tests, by grinding with progressively finer silicon carbide papers (\#800-\#4000), and polishing with $1 \mu \mathrm{m}$ diamond compound; finally, the specimens were cleaned with acetone and dried in air. After the mechanical polishing procedure the specimens were analyzed by a 3-D optical profilometer (Infinite Focus, Alicona, Austria) to ensure that the surface finish was within acceptable limits for micro indentation measurements.

Indentation tests were carried out at room temperature, using a spherical indenter $(\mathrm{R}=25 \mu \mathrm{m})$, as a sharp tip indenter (such as Berkovich, Vickers, etc.), causes high strain gradients immediately beneath the indenter which promote plastic deformation, which inhibits the subsequent reverse transformation from martensite to the parent phase. In fact, previous research [11] has demonstrated that there is no evidence of superelastic recovery upon unloading when a Berkovich indenter is used, while a large recovery is observed when using a spherical tip indenter. Preliminary indentation tests were performed to identify optimum test parameters, such as maximum load range, loading/unloading rate and dwell time, in order to reduce measurement errors and avoid creep effects on the P- $\delta$ curve.

Several indents were made at increasing values of maximum load (50,150, 300 and $450 \mathrm{mN}$ ), with a loading/unloading rate of $2.5 \mathrm{mNs}^{-1}$ and a holding time of 60 seconds at the maximum load; furthermore, a set of 20 indentations were carried out for each value of the maximum load, so as to capture the average response of the material, i.e. to analyze different grains of the polycrystalline structure. 


\section{FINITE ELEMENT MODELING}

$\mathrm{F}$ inite Element Analyses (FEA) have been carried out, by using a commercial FE software code and a special SMA constitutive model $[16,17]$ in order to study the microstructural evolution during indentation tests as well as to estimate the evolution of the indentation response of the alloy as a function of the test temperature. In particular, two-dimensional axisymmetric FE analyses were carried out by exploiting the axisymmetry of the indenter, while the sample was assumed to be a cylinder with radius equal to 10 times the diameter of the indenter, in order to avoid boundary effects [18]. The model, illustrated in Fig. 2, consists of approximately 50400 2D four-noded quadrilateral elements. The figure also illustrates that a very fine mesh has been used to model the contact region in order to capture the high stress gradient and the complex non-linear effects due to plastic deformation and stress-induced transformation mechanisms, in addition to those due to the contact. This model results from a preliminary convergence study, which was developed by analyzing a standard elastic-plastic material; in particular, systematic comparisons between numerical results and elastic-plastic contact theory have been carried out in order to obtain an optimal balance between accuracy and computational efficiency.

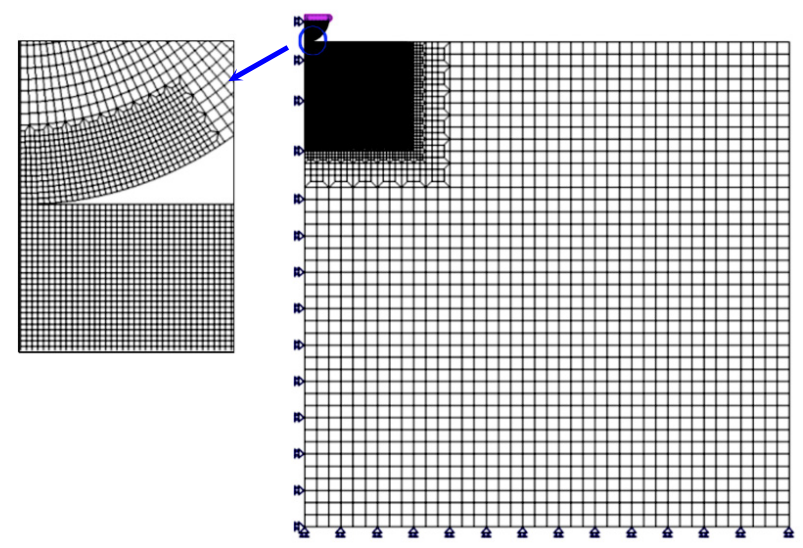

Figure 2: Axisymmetric FE model used to analyze the indentation process.

Subsequently, the constitutive model for SMAs, which is directly implemented in the numerical code, was calibrated using the thermo-mechanical parameters illustrated in the previous section, while linear elastic behavior has been adopted for the diamond indenter (elastic constant: $\mathrm{E}=1141 \mathrm{GPa}, v=0.07$ ). The numerical results were compared with the experimentally measured load-displacement curves and, subsequently, the influence of test temperature on the indentation response of the SMA has been numerically analyzed, as described in the following section.

\section{RESULTS AND DISCUSSIONS}

\section{Preliminary FE analysis}

$\mathrm{P}$ reliminary FE studies have been carried out to investigate the phase transition mechanisms in the indentation region as well as to understand better the main differences with respect to conventional elastic-plastic metals. Fig. 3.a illustrates the transformation boundaries in the contact region, for a maximum load of $300 \mathrm{mN}$, which have been obtained from the FE simulations by comparing the von Mises equivalent stress with the characteristic transformation stresses of the SMA. Starting from the outer region, a fully untransformed austenitic zone is observed (A), i.e. where the von Mises stress is below the start transformation stress $\sigma<\sigma_{A M}^{s}$. The area B represents the transformation zone, i.e. von Mises stress between $\sigma_{A M}^{s}$ and $\sigma_{A M}^{f}$ and consequently the volume fraction of martensite is between 0 and 1. Finally, $\mathrm{C}$ and $\mathrm{D}$ represent the fully transformed martensitic regions, i.e. where the von Mises stress is higher than the transformation stress, $\sigma_{A M}^{f}$; however, in $\mathrm{C}$ only elastic deformation of the martensitic structure is observed while in $\mathrm{D}$ the local stress exceeds the yield stress of martensite and permanent deformation is observed leading to stabilization of the martensite. This stabilized martensite does not revert to austenite on unloading. It is worth noting that the contours in 
Fig. 3.a represent an average estimate of the different regions near the indenter, i.e. they are obtained from the macroscopic stress field and do not take into account the real microstructure of the alloy. In fact, local stress-induced transformation mechanisms, due to different orientations of the martensite variants, and dislocation movement, could occur around the contact region as a consequence of the stress field. Fig. 3.b presents a comparison of the indented profile of a SMA and an equivalent elastic-plastic material having the same Young's modulus as the austenite phase and a yield stress equal to the start transformation stress $\sigma^{Y}=\sigma_{A M}^{s}$. In particular, the profiles at the maximum load of $300 \mathrm{mN}$ and upon unloading, normalized with respect to the maximum depth, are compared. The figure clearly illustrates a smaller residual depth in the SMA after unloading, i.e. it exhibits higher recovery deformation as a consequence of the reversible stress-induced martensitic transformation in the indentation region. In fact, the recovery mechanisms in SMAs can be attributed to both elastic and pseudoelastic properties.

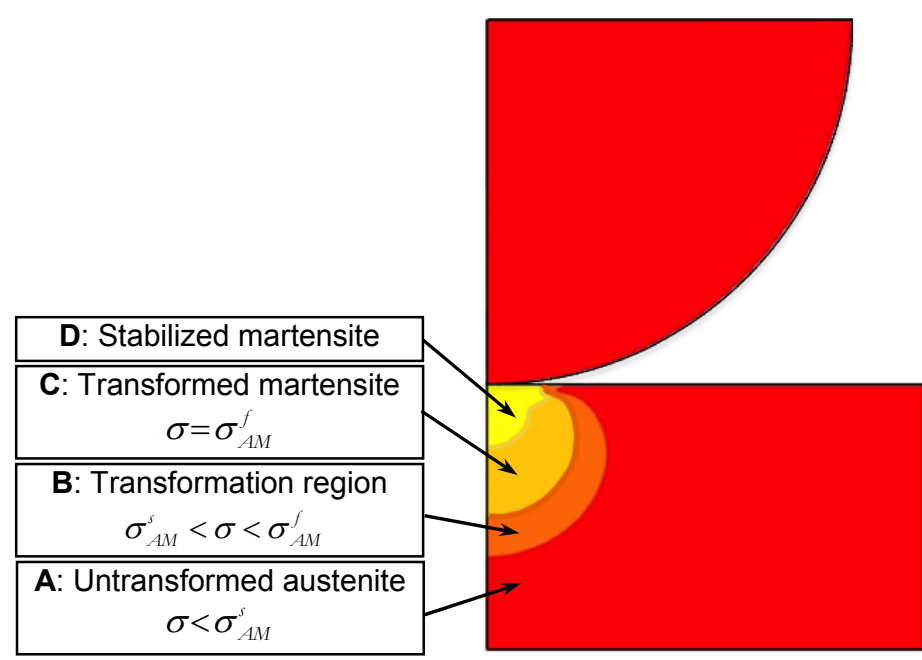

a)

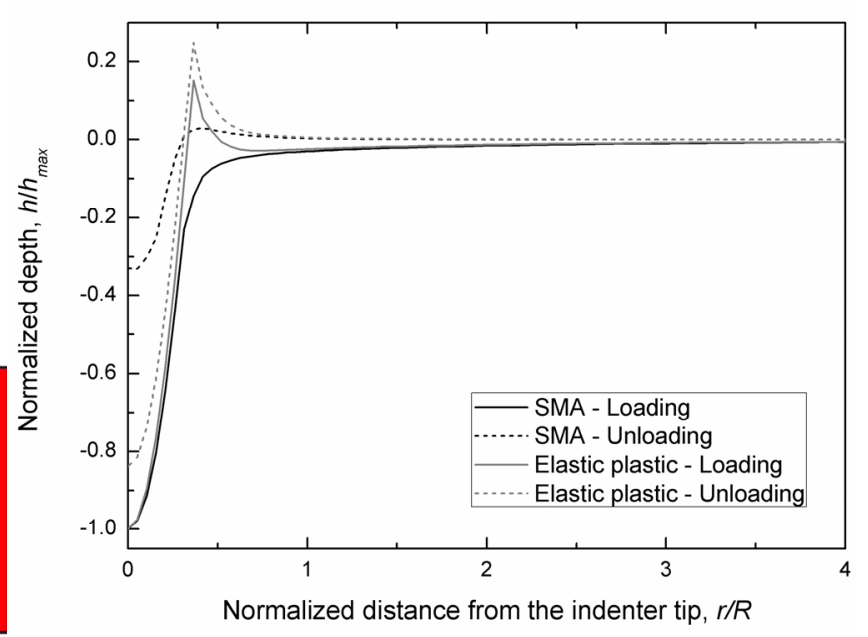

b)

Figure 3: Preliminary FE results: a) stress-induced transformation contours near the contact region; b) comparison of the indentation profile between an elastic-plastic material and a SMA.

\section{Indentation tests}

Fig. 4 shows the load-displacement $(\mathrm{P}-\delta)$ curves obtained from indentation tests carried out at increasing values of maximum load: $50 \mathrm{mN}$ (a), $150 \mathrm{mN}$ (b), $300 \mathrm{mN}$ (c) and $450 \mathrm{mN}$ (d). It is worth noting that good repeatability of the P- $\delta$ curves was observed, especially at higher values of indentation load; this results from an optimal choice of the test parameters. In fact, the load-displacement curves become smoother and differences between repeat tests decrease with increasing indentation load, due to both a reduction in experimental errors and the greater amount of material undergoing phase transformation.

The reversible stress-induced phase transition mechanisms are also demonstrated by the pop-out events [18] which occur in the unloading stage. In addition, as observed from the preliminary FE simulations, the residual depth upon unloading is a useful measure of the functional behavior of the SMA in terms of its pseudoelastic recovery capability. Fig. 5.a shows the values of the maximum depth $\left(h_{\max }\right)$, residual depth $\left(h_{r}\right)$ and residual depth ratio $\left(h_{r} / h_{\max }\right)$ as a function of the indentation load. The figure illustrates that both the residual depth and the residual depth ratio increase with increasing indentation load, which indicate an overall reduction of the pseudoelastic response of the SMA due to an increased volume fraction of dislocations and stabilized martensite (region D in Fig. 3.a) immediately beneath the indented surface. Similar considerations can be made from an energetic point of view, as illustrated in Fig. 5.b. Specifically, this figure presents the recovery energy $\left(E_{e}\right)$, i.e. the energy associated with the unloading path, the dissipated energy $\left(E_{d}\right)$, i.e. the area between loading and unloading curve, the total energy $\left(E_{t}=E_{e}+E_{d}\right)$, the recovery energy ratio $\left(E_{e} / E_{t}\right)$ and the dissipated energy ratio $\left(E_{d} / E_{t}\right)$ as a function of the indentation load. The figure clearly shows an increase of both dissipated and recovery energy with increasing indentation load, which indicate an overall increase of both permanent and recovery deformation, as is also illustrated in Fig. 5.a. Fig. 5.b shows that the difference between the recovery energy and dissipated energy increases gradually with indentation load above $150 \mathrm{mN}$. This indicates that, although the residual depth increases with increasing load (Fig. 5.a) the recovery energy also increases counteracting the energy dissipated in the formation and movement of dislocations. Fig. 5.b also demonstrates almost constant values of the Dissipated energy ratio and the 
Recovery energy ratio for indentation loads above $150 \mathrm{mN}$. This suggests that the greater amount of material stressed reversibly at higher indentation loads, and thus the greater recovery energy available, balances the increased amount of dissipated energy involved in the indentation process at higher indentation loads. Although plastic deformation beneath the indenter reduces the amount of shape recovery this plastically deformed material decreases the stress gradient in the material surrounding the plastically deformed volume favoring the reverse phase transformation.
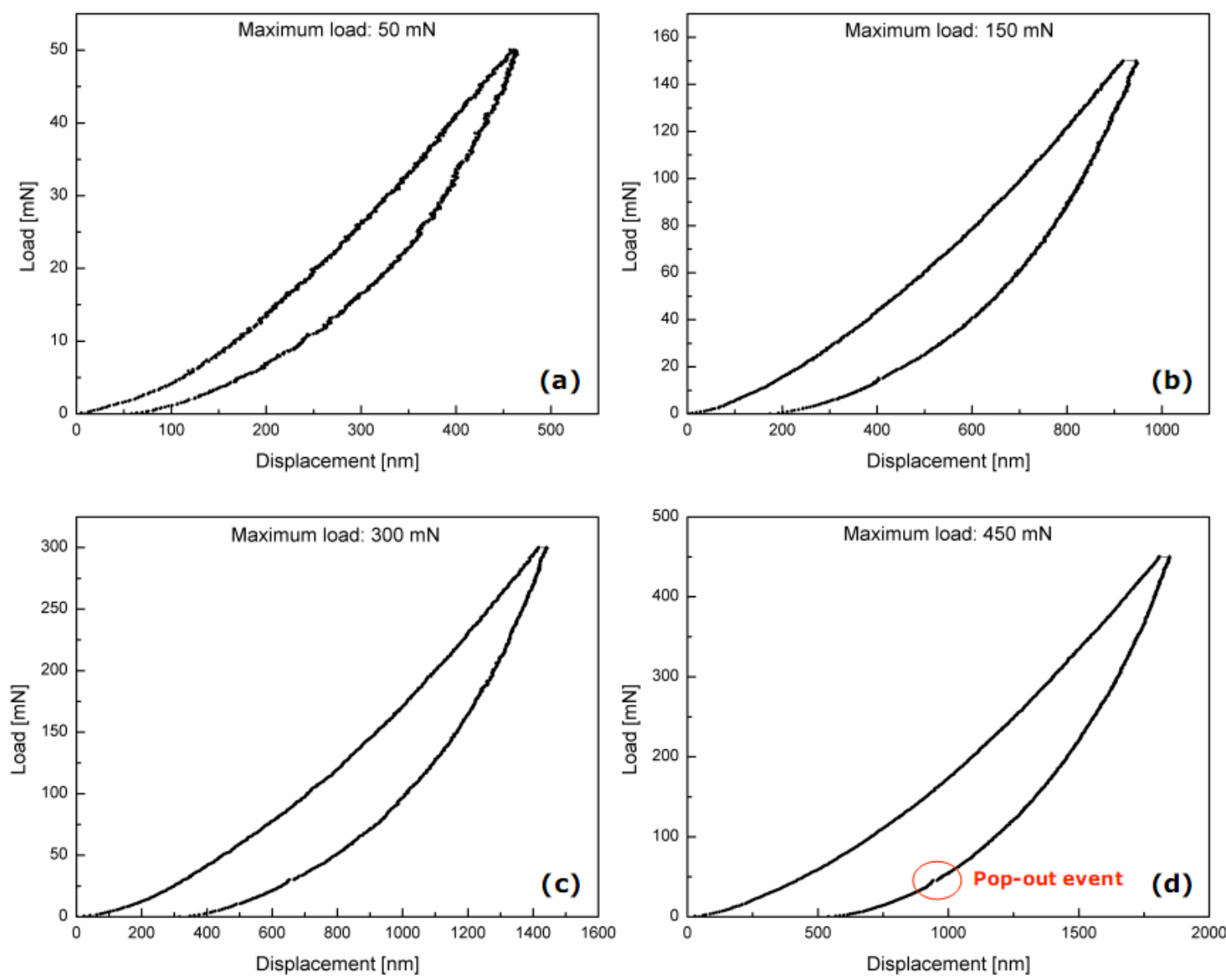

Figure 4: Single quasi-static indentation tests for different values of maximum load:

(a) $50 \mathrm{mN}$, (b) $150 \mathrm{mN}$, (c) $300 \mathrm{mN}$ and (d) $450 \mathrm{mN}$

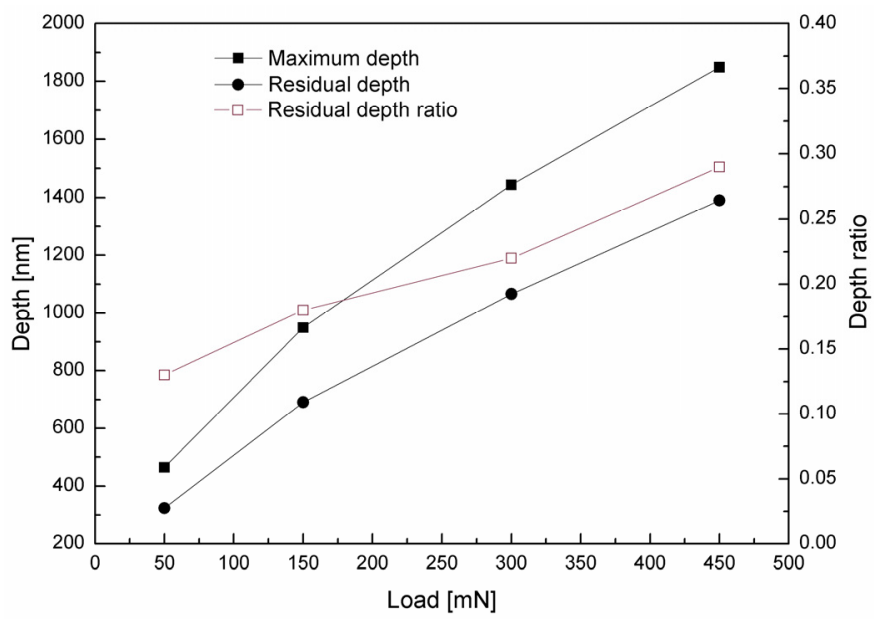

a)

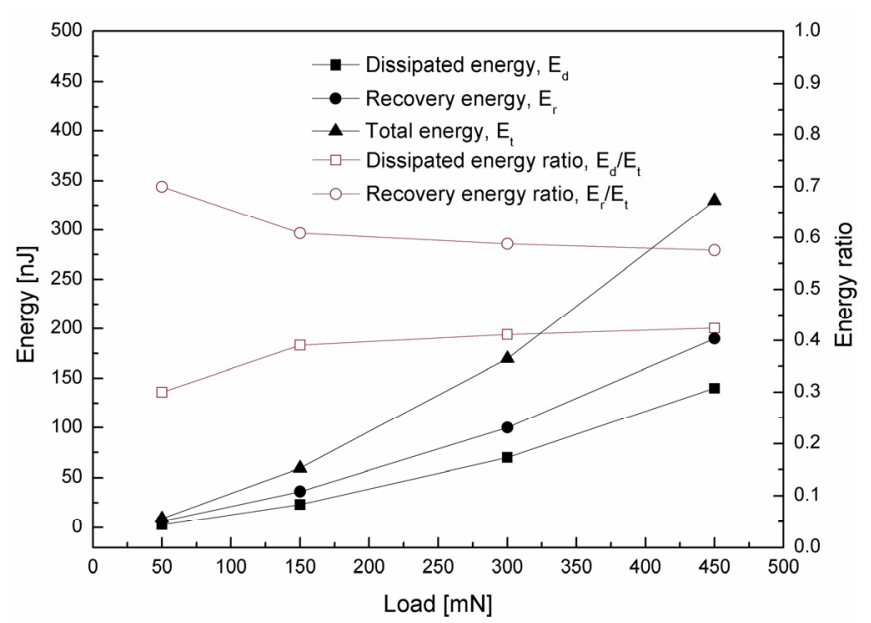

b)

Figure 5. Recovery and residual capability of the SMA after unloading: a) depth recovery and b) energy recovery. 


\section{Effects of test temperature}

The effects of test temperature on the indentation response of the SMA have been analyzed by FE simulations by using the Clausius-Clapeyron relationship to calculate the relevant transformation stresses. To that end the FE model was first validated by comparison with experimental measurements carried out at room temperature, as it was not possible to perform indentation tests under temperature-controlled conditions. Fig. 6 compares the load-displacement curves obtained from FE simulation and experiment for indentation at room temperature to a maximum load of $300 \mathrm{mN}$. The figure clearly illustrates good agreement between the numerical results and experiments in terms of both maximum depth and residual depth, as well as in terms of the recovery and dissipated energy.

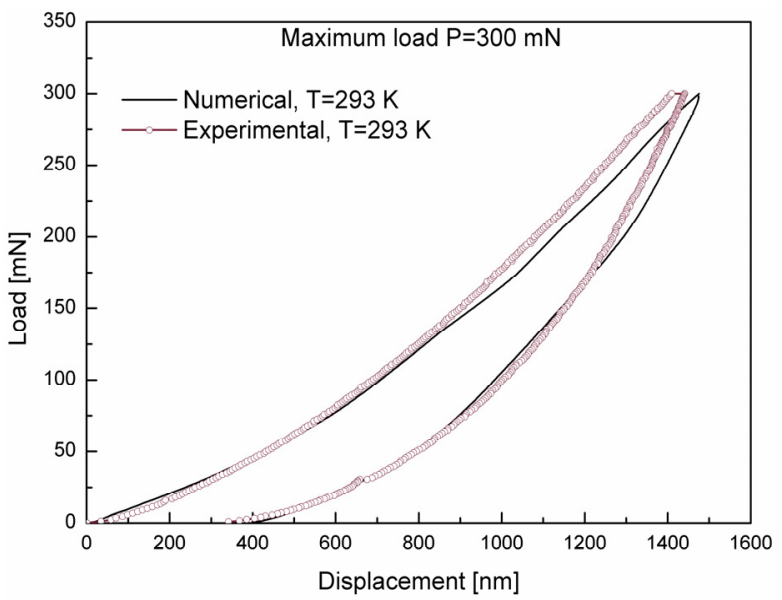

Figure 6: Comparison of the Load-Displacement curves obtained from FE simulations and experimentally measured $(\mathrm{T}=293 \mathrm{~K}, \mathrm{P}=300$ $\mathrm{mN})$.

Fig. 7 shows the load-displacement curves obtained for different test temperatures ( $T=293 \mathrm{~K}, \mathrm{~T}=303 \mathrm{~K}, \mathrm{~T}=313 \mathrm{~K})$ for an indentation load of $300 \mathrm{mN}$. As expected, a marked effect of temperature on the indentation response of the SMA is observed, in terms of both maximum depth and residual depth, which is a direct consequence of the changes in transformation stresses of the alloy. The evolution of these parameters as a function of temperature and the direct transformation stress $\left(\sigma_{A M}^{s}\right)$ for an indentation load of $300 \mathrm{mN}$ is illustrated in Fig. 7.b.

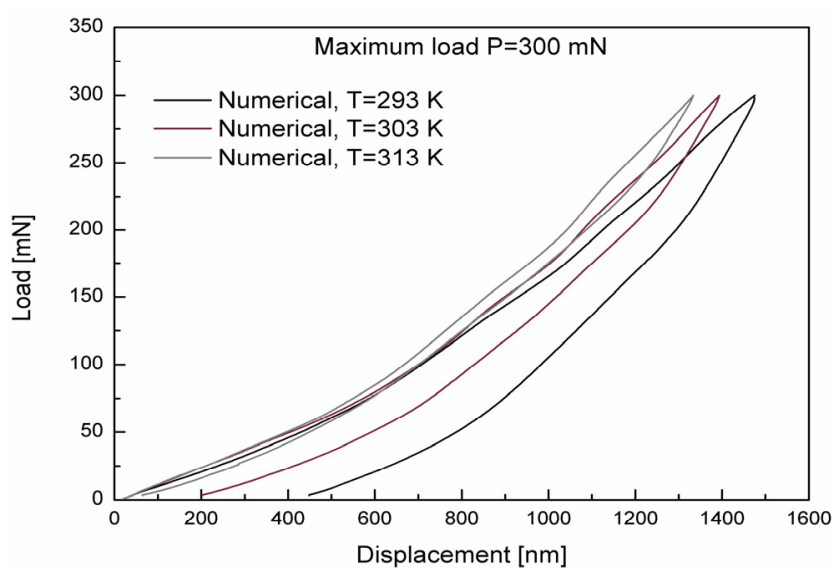

a)

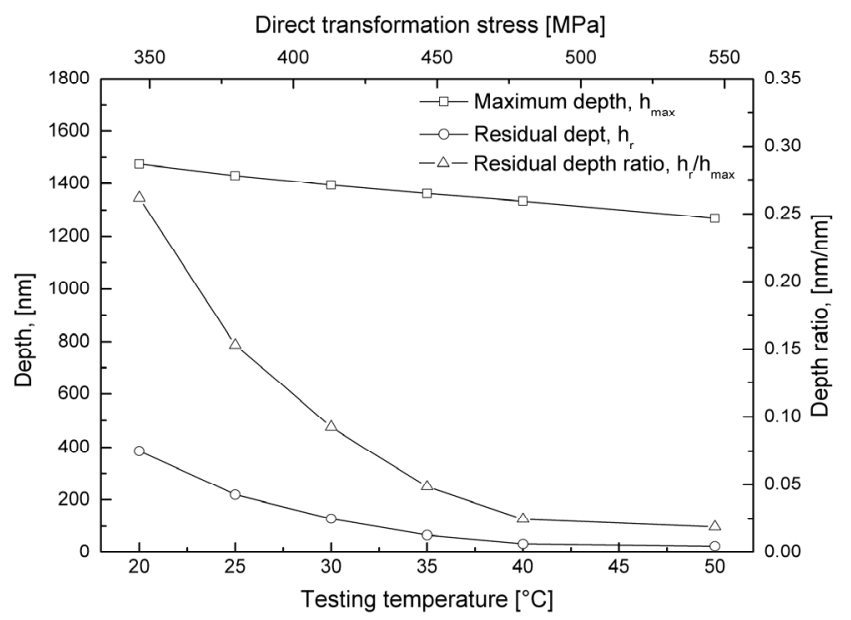

b)

Figure 7. Effects of test temperature on the indentation response of the SMA: a) Load-Displacement curves of the SMA at different temperatures; b) Maximum depth and residual depth vs temperature and direct transformation stress.

The figure shows a reduction of both maximum depth and residual depth with increasing test temperature; however the residual depth decreases more rapidly, which indicates an overall improvement of the pseudoelastic response of the SMA 
and an associated reduction in the amount of stabilized martensite present resulting from the increase of transformation stresses with temperature.

\section{CONCLUSIONS}

$\mathrm{T}$ he indentation response of a pseudoelastic NiTi shape memory alloy (SMA) has been analyzed in this study, by experimental measurements and numerical simulations. Single quasi-static indentation tests have been carried out and load-displacement data have been analyzed to obtain valuable information on the pseudoelastic response of the alloy. In addition, numerical simulations have been carried out to understand better the microstructural evolution occurring during the indentation process, as well as to analyze the effects of test temperature on the indentation response of the SMA. The main results of this study are summarized as follows:

$\checkmark$ Stress induced transformation mechanisms occur in the indentation region, as demonstrated by the preliminary FE simulations, which significantly affect the indentation response of SMAs with respect to conventional elastic plastic materials;

$\checkmark$ A spherical indenter should be used in order to promote a large stress-induced transformation zone in the indentation region and, consequently, to avoid local effects due to microstructural variations. This allows the overall macroscopic response of the alloy to be measured;

$\checkmark$ The volume fraction of stabilized martensite immediately beneath the indented surface increases with increasing indentation load in single quasi-static tests, which results in an overall reduction of the shape recovery during unloading;

$\checkmark$ The functional behavior of NiTi superelastic alloys is clearly governed by an energy balance between martensite formation and the plastic deformation involved in the indentation process.

$\checkmark$ Systematic finite element (FE) studies revealed a significant effect of the test temperature and the corresponding transformation stress on the indentation response of the alloy in terms of both maximum and residual depth.

\section{REFERENCES}

[1] K. Otsuka, X. Ren, Progr. Mater. Sci., 50 (2005) 511.

[2] W.C. Oliver, G.M. Pharr, J. Material Res., 7 (1992) 1564.

[3] G. Satoh, A. Birnbaum, Y.L. Yao, In: Proc. Of Int. Congress on Applications of Lasers and Electro-Optics, Temecula CA (2008).

[4] P.D. Tall, S. Ndiaye, A.C. Beye, Z. Zong, W.O. Soboyejo, H.J. Lee, A.G. Ramirez, K. Rajan, Mater. Manuf. Processes, $22(2007) 175$.

[5] A.K. Nanda Kumar, C.K. Sasidharan Nair, M.D. Kannan, S. Jayakumar, Mater. Chem. Phys., 97 (2006) 308.

[6] G.A. Shaw, W. C. Crone, Mater Res Soc Symp Proc., 791 (2003) 215.

[7] W.C. Crone, G.A. Shaw, D.S. Stone, A.D. Johnson, A.B. Ellis, In: Society for Experimental Mechanics, SEM Annual Conference Proceedings, Carlotte, NC (2003).

[8] G.A. Shaw, D.S. Stone, A.D. Johnson, A.B. Ellis, W.C. Crone, Appl. Phys. Lett., 83 (2003) 257.

[9] C. Liu, Y.P. Zhao, T. Yu, Mater. Design, 26 (2005) 465.

[10] C. Liu, Y. Zhao, Q. Sun, T. Yu, Z. Cao, J. Mater. Sci., 40 (2005) 1501.

[11] A.J. M. Wood, T.W. Clyne, Acta Materialia, 54 (2006) 4607.

[12] A.J.M. Wood, J.H You, T.W. Clyne, Proc. SPIE, 5648(39) (2205) 216.

[13] W. Yan, Q. Sun, X.Q. Feng, L. Qina, Int. J. Solids Struct., 44 (2007) 1.

[14] M. Arciniegas, Y. Gaillard, J. Pena, J.M. Manero, F.J. Gil, Intermetallics, 17 (2009) 784.

[15] R. Liu, D.Y. Li, Y.S. Xie, R. Llewellyn, H.M. Hawthorne, Scripta Materialia, 41(7) (1999) 691.

[16] M. Saeedvafa, A Constitutive Model for Shape Memory Alloys, Internal MSC Report (2002).

[17] M. Saeedvafa, R.J Asaro, LA-UR-95-482, Los Alamos Report, (1995).

[18] A.C. Fisher-Cripps, Nanoindentation, Second Edition, Springer (2002). 